\title{
Speculative Devices for Photo Display
}

\author{
Abigail Durrant \\ Digital World Research Centre \\ University of Surrey \\ Guildford, GU2 7XH, UK \\ a.durrant@surrey.ac.uk \\ Alex S. Taylor \\ Microsoft Research Cambridge \\ 7 J J Thomson Ave \\ Cambridge, CB3 OFB, UK \\ ast@microsoft.com

\section{Stuart Taylor} \\ Microsoft Research Cambridge \\ 7 J J Thomson Ave \\ Cambridge, CB3 OFB, UK \\ stuart@microsoft.com

\section{Mike Molloy} \\ Microsoft Research Cambridge \\ 7 J J Thomson Ave. \\ Cambridge, CB3 OFB, UK \\ v-mimoll@microsoft.com \\ Abigail Sellen \\ Microsoft Research Cambridge \\ $7 \mathrm{~J}$ J Thomson Ave \\ Cambridge, CB3 OFB, UK \\ asellen@microsoft.com

\section{David Frohlich} \\ Digital World Research Centre \\ University of Surrey \\ Guildford, GU2 7XH, UK \\ d.frohlich@surrey.ac.uk

\section{Phil Gosset} \\ Microsoft Research Cambridge \\ 7 J J Thomson Ave \\ Cambridge, CB3 OFB, UK \\ v-phgoss@microsoft.com

\section{Laurel Swan} \\ Microsoft Research Cambridge \\ $7 \mathrm{~J}$ J Thomson Ave \\ Cambridge, CB3 OFB, UK \\ v-laurs@microsoft.com \\ Copyright is held by the author/owner(s). \\ CHI 2008, April 5 - April 10, 2008, Florence, Italy \\ ACM 978-1-60558-012-8/08/04.
}

\begin{abstract}
In this paper, we describe three purposefully provocative, digital photo display technologies designed for home settings. The three devices have been built to provoke questions around how digital photographs might be seen and interacted with in novel ways. They are also intended for speculation about the expressive resources afforded by digital technologies for displaying photos. It is hoped interactions with the devices will help researchers and designers reflect on new design possibilities. The devices are also being deployed as part of ongoing home-oriented field research.
\end{abstract}

\section{Keywords}

Photo displays, digital photography, domestic IT, home, interaction design, critical design

\section{ACM Classification Keywords}

H5.m. Information interfaces and presentation (e.g., $\mathrm{HCI}$ ): Miscellaneous.

\section{Introduction}

Much research has been directed towards investigating the practices associated with both paper and digital photographs. Most noted, perhaps, is the work from Frohlich and his colleagues on photo sharing [2] and Frohlich's later but related ideas on audiophotography [1]. Various efforts have been pursued to develop and extend this work empirically [e.g., 3], technically [e.g., 
6], and in terms of usability [e.g., 9]. In parallel, other photo-related research has considered, for example, the work involved in managing, organising and archiving pictures once taken [5], as well as the mechanics of photo sharing using particular technologies such as instant messaging [13] or mobile phones [7].

Given the plethora of research in this area, it is surprising to find so little attention given to the situated display of photos-that is, how photos are displayed in particular contexts and how different display technologies might afford different ways of seeing, interpreting and interacting with photographic content. Such an inquiry is deemed timely given the emerging new practices and services surrounding digital photo display [e.g., 8]. Turning to the HCI and Ubicomp literature, it's evident that a limited number of projects and studies have considered photo display design. These, however, have broadly aimed to tackle the problems of distributing photos between remote displays [e.g., 6], sometimes to support capabilities like remote awareness [e.g., 11], rather than to explore the specific properties or interactional features of the display technologies themselves.

\section{Photo Display Interactions}

The designs outlined in this paper represent our recent efforts to investigate how technologies might support photo display in novel ways. These design explorations form a collaborative endeavour between the Digital World Research Centre at the University of Surrey and the Social Digital Systems Group at Microsoft Research Cambridge. The presented work runs alongside and is informed by ongoing empirical field studies investigating photo displays in family homes [see 12].
The demonstration itself is made up of three displays. Alone, each of these displays might appear technically and functionally simple. However, they should be seen together as a collection of interconnected devices and illustrative of an extensible platform of networked digital display technologies. In this way, they embody a ubiquitous computing model of multiple interactive surfaces, whereby the relatively simple interactional properties of each device combine to enable diverse and sometimes complex possibilities for displaying photos.

Another reason for the simplicity of each display design is to support the current exploratory stage of our research. Crucially, the purpose of the presented designs is not to determine a 'solution' to digital photo display. Instead, our aim is to use design as a means to critically think through the practices related to the situated display of photos within the home. In other words, the designs are not so much an end goal, as they are a speculative resource to open up spaces for further design. For example, from the outset we wonder: what does it mean to experience a dynamic versus a static photo display? Our use of design, in this sense, draws on the critical design approach outlined by Dunne [4] and put into practice in the $\mathrm{HCI}$ field by Martin and Gaver [10], amongst others.

The three concepts illustrated here are intended, then, to provoke questions around particular forms of interaction and use by both individual and groups of users. Collectively, the three displays are presented in order to examine the interrelations between digital displays and how these interrelations might be closely tied to the specific features of each display. The point here is not to merely demonstrate an ability to transfer 
photos between displays, but rather to prompt careful consideration of what influence displays might be designed to have over one another in everyday use. Thus, together, our design ideas are intended to encourage exploration into a repertoire for arranging and displaying digital photo collections. Below, we describe the specific features of the displays and their connectivity, and how we have conceived of each to speculate on a range of interactional properties.

\section{Display platform}

The three concepts below are designed to display digital photos stored on a central archive. The archive can reside on one of the three display devices or on a remote computer. The displays and, if necessary, the remote computer are distributed over a common wireless network. The specific interactional features of each display dictate which photos are to be copied from the central archive and when they are to be displayed (detailed below). This 'platform' for speculative photo displays is built using an extensible architecture so that additional displays, each offering a distinctive set of features, can be added incrementally.

\section{Photomesh}

Photomesh is a wall-mounted (or potentially hand-held) device designed to display several photos simultaneously in a collage-like arrangement. When left in one place, it behaves as an ambient or peripheral display, with its content cycling through photos taken from the central archive in a 'random' fashion.

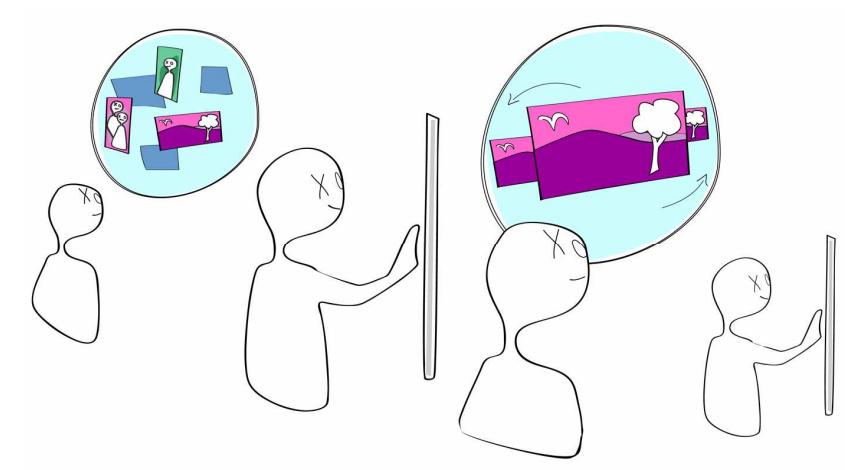

Figure 1a. Illustration of Photomesh display: users either view a collage of digital photos in a 'random' fashion or move through them in chronological sequence.

However, the surface of the device is touch sensitive and also allows a 'walk-up' set of interactions: a specific photo can be selected from the collage and enlarged across the surface area; and a user or group of users can then make intuitive gestures to navigate back and forth through the archive in a chronological sequence (Fig. 1a). In a simple way, Photomesh experiments with how displays may support a shift in engagement from periphery to foreground, and from a multiple to single image-viewing platform. 


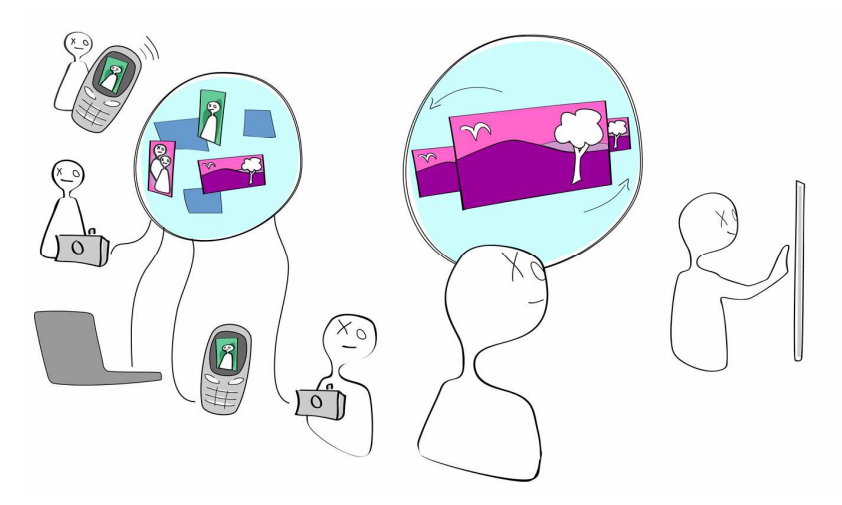

Figure 1b. Illustration of Photomesh: photos can be uploaded using USB cables or wireless connections (i.e. Bluetooth).

By providing a number of USB ports, wireless connectivity and an automatic upload feature (Fig. 1b), Photomesh also offers a lightweight method for uploading photos from capture devices such as cameras and mobile phones to both the displayed collage and larger central photo archive.

\section{Photoillume}

Photoillume takes the form of a portable display frame for single image viewing. The display comprises an LCD screen that fades to black if the device is moved into relative darkness. Returning the device to light retrieves and displays another photo from the central archive. Thus, a screen must be tended to, as it were, to ensure a photo remains visible and its display perpetuated. It is envisaged that several Photoillume displays might be associated with a single photo archive.

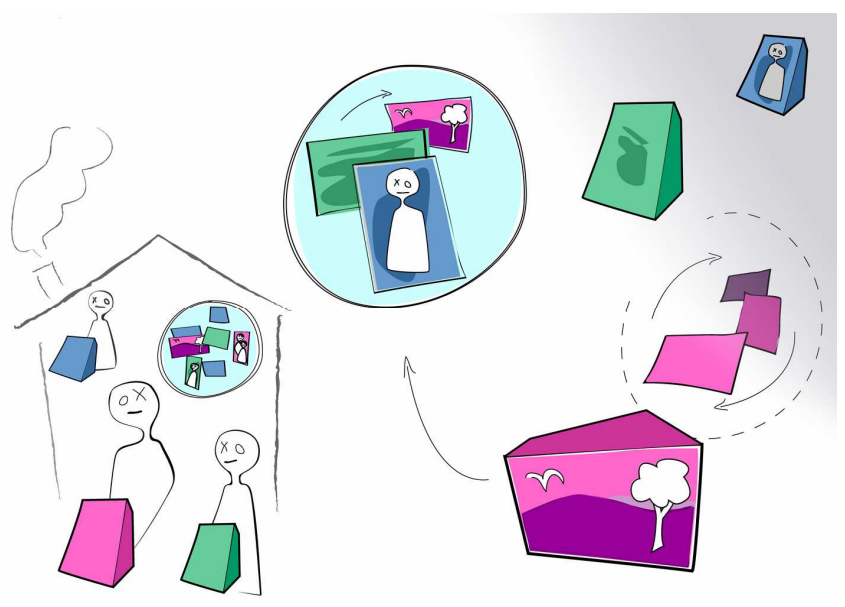

Figure 2. Illustration of Photoillume: household members keep a photo on display by placing the device in the light. When in shadow (relative dark), the photo fades to black.

Photoillume has also been designed to integrate with Photomesh: the longer photos are displayed on Photoillume(s) the lesser their visible presence in the Photomesh collage. Thus, in tending to Photoillume, users set up a playful inter-relationship with another physically remote display.

\section{Photoswitch}

Photoswitch comprises a casement with two photo display regions and a sliding door that constrains viewing to no more than one region at a time. A photo displayed on the region behind the door starts to fade to black over time, at which point it is replaced by another photo from the central archive. Sliding the door again before this point causes the faded photo to return to its original brightness but after this point reveals a new photo from the archive (Fig. 3). 
Consequently, there is always a tension between leaving a photo on display and viewing a new photo.

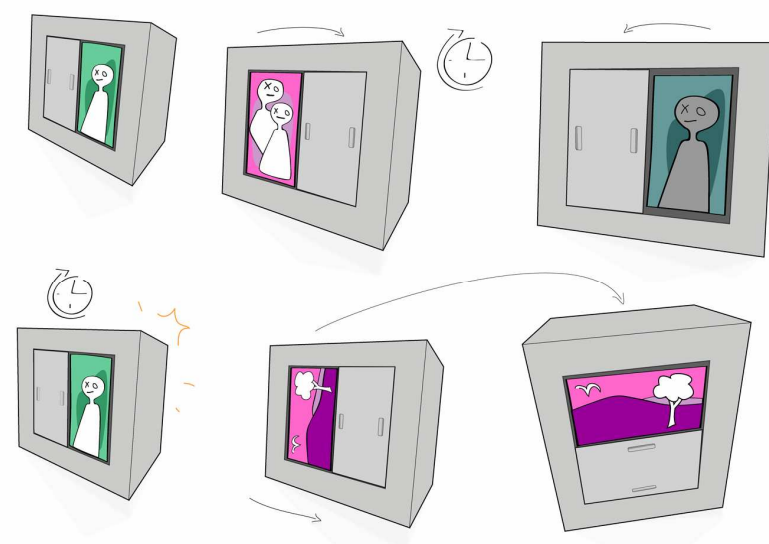

Figure 3. Illustration of Photoswitch: viewing is constrained to one photo at a time; and sliding the door affects the photo displayed.

Display gestures using Photoswitch are reflected on Photoillume devices; once a photo has been removed from Photoswitch, it is placed in a queue to be displayed on a Photoillume device. In this way, discarded Photoswitch photos are given prominence elsewhere, possibly with unwanted side effects.

\section{Conclusion}

To reiterate, the outlined display demonstration is presented as illustrative of a larger program of research investigating the possibilities for novel photo displays. (See 12 for an extended review.) The three devices above have been purposefully designed in order to raise questions about the use of photo display technologies and how they may be incorporated into people's routine photo display practices.

Thus, in designing the devices, particular emphasis has been given to their speculative and in some cases provocative character. They are meant to provoke questions around the following themes: how households collaborate in arranging photos for display; how particular obligations and accountabilities are made visible through displays; and the ways in which 'curatorial control' is exerted and embodied in the choices and arrangements of displays. These themes have been identified in previous research as salient to displaying photos in households [see 12]. For example, through its material affordances (such as the sliding door), Photoswitch invites its users to enter negotiations about which photo to display when from the household collections. By presenting a particular context for making such choices, Photoswitch draws attention to the dynamic nature of digital display technologies in general and the tensions surrounding the temporal display of photos, which, as we have found, relate to obligation and control issues within the home. Photoswitch enables us to explore how these tensions are played out using digital technology in a novel configuration that specifically affords - highlights, even - the temporal display of photos.

Using the above designs to provoke questions in this way, our hope is not only that we, alone, develop and build on the aforementioned themes of collaboration, obligation and control (as well as others). We also aim to sensitise ourselves, as researchers, to the affordances of digital technology in relation to these themes. By exhibiting these three devices to a research 
and design audience, there is an explicit intention to receive informed feedback on our explorations.
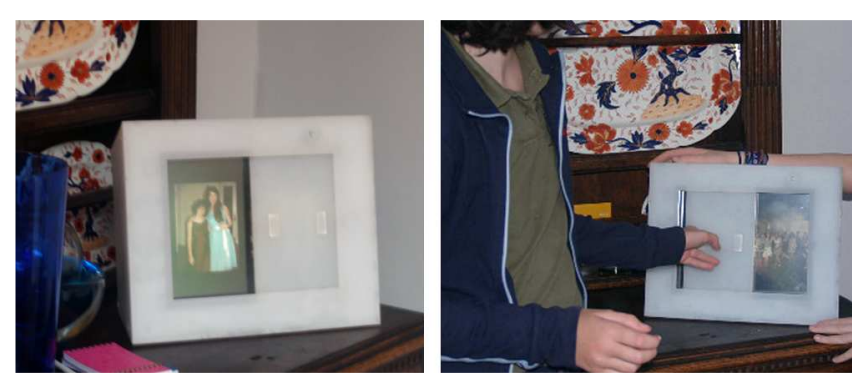

Figure 4. Deployment of Photoswitch in a family home.

Alongside our own reflections, we want to sensitise our research participants to our themes in terms of how photo display technologies afford different kinds of everyday expression. We are currently exploring use of the three designs in situ through their deployment in people's homes (Fig. 4).

\section{Acknowledgments}

Presented research is supported in part by the Microsoft European PhD Scholarship Programme.

\section{References}

[1] Frohlich, D. M. Audiophotography: Bringing Photos to Life with Sounds. Kluwer Academic Press, Dordrecht, 2004.

[2] Frohlich, D., Kuchinsky, A., Pering, C., Don, A., \& Ariss, S. Requirements for photoware. Proc. CSCW 2002, ACM Press (2002), 166-175.

[3] Crabtree, A., Rodden, T., \& Mariani, J. Collaborating around collections: informing the continued development of photoware. Proc. CSCW 2004, ACM Press (2004), 396-405.

[4] Dunne, A. Hertzian Tales: Electronic Products, Aesthetic Experience, and Critical Design, MIT Press, Cambridge, MA, 2006.

[5] Kirk, D., Sellen, A., Rother, C., and Wood, K. Understanding photowork. Proc. CHI 2006, ACM Press (2006), 761-770.

[6] Kim, J. and Zimmerman, J. Cherish: smart digital photo frames for sharing social narratives at home. Ext Abstracts CHI 2006, ACM Press (2006), 953-958.

[7] Kindberg, T., Spasojevic, M., Fleck, R., \& Sellen, A. The Ubiquitous Camera: an In-Depth Study of Camera Phone Use. IEEE Pervasive Computing, 4, 2 (2005), 4250.

[8] Lampe, C., Ellison, N. \& Steinfield, C. A Familiar Face(book): Profile Elements as Signals in an Online Social Network. Proc. CHI 2007, ACM Press (2007), 435-444.

[9] Lindley, S. \& Monk, A. Designing appropriate affordances for electronic photo sharing media. Ext Abstracts CHI 2006, ACM Press (2006), 1031-1036.

[10] Martin, H. \& Gaver, W. Beyond the Snapshot: From Speculation to Prototypes in Audiophotography. Proc. DIS 2000, ACM Press (2000), 55-65.

[11] Mynatt, E. D., Rowan, J., Jacobs, A., \& Craighill, S. Digital Family Portraits: Supporting Peace of Mind for Extended Family Members. Proc. CHI 2001, ACM Press (2001), 333-340.

[12] Taylor, A. S., Swan, L. and Durrant, A. Designing family photo displays. Proc. ECSCW 2007. SpringerVerlag Press (2007), 79-99.

[13] Voida, A. and Mynatt, E. D. Six themes of the communicative appropriation of photographic images. Proc. CHI '05, ACM Press (2005), 171-180. 